\title{
TEMPOS DE CIBERCULTURA, NARRATIVAS DIGITAIS E CURRÍCULO, POTENCIALIDADES EDUCATIVAS: DIÁLOGOS OUTROS PARA A FORMAC̣ÃO HUMANA EM TEMPOS DE DISTANCIAMENTO SOCIAL
}

\author{
Nádson Araújo dos Santos ${ }^{1}$ \\ Adriana Cavalcanti dos Santos ${ }^{2}$
}

VIANA, Maria Aparecida Viana; SILVA, Givanildo da. Tempos de cibercultura, narrativas e currículo: potencialidades educativas (Orgs). Maceió: Edufal, 2019.

As tecnologias digitais (TD) são parte do nosso contexto social na atualidade. Pesquisas recentes como as de Santos, Santos e Santos (2020), Santos e Cavalcante (2019) e Pimentel e Costa (2017) demonstram que elas - as tecnologias digitais - fazem parte das "novas" formas de comunicação por meio do uso da linguagem em práticas sociais e educacionais do Brasil.

Nesse contexto, resenhamos a coletânea "Tempos de Cibercultura, Narrativas Digitais e Currículo: potencialidades educativas" organizada pelos professores: Maria Aparecida Pereira Viana, Doutora em Educação - currículo (PUC-SP), professora do Centro de Educação da Universidade Federal de Alagoas; e Givanildo da Silva, Doutor em Educação (UFPB), também professor do Centro de Educação da Universidade Federal de Alagoas (UFAL).

A obra é organizada por nove capítulos que se complementam em torno da relação entre cibercultura, narrativas e currículo. Os discursos defendidos capítulo a capítulo focam nos usos das tecnologias digitais em contextos educacionais, promovendo uma reflexão sobre a dissociabilidade de pensar-se na escola a abordagens das TD e o(s) currículo(s).

Na leitura da Obra é pertinente realizar diálogos outros com os postulados defendidos pelos autores dos nove capítulos, sobretudo, no que se refere ao contexto que se aplica ao cenário educacional nacional e internacional na atualidade, tempos de pandemia e distanciamento social ${ }^{3}$, pondo em cheque todas as discussões e contribuições das tecnologias digitais para a educação, levando os profissionais da educação a refletirem de que modo, esse conhecimento pode ser fundamental para ações de escolas e professores, seja na educação básica ou no ensino superior.

No primeiro capítulo, intitulado "Narrativas digitais na formação de professores: o uso do software Nvivo 11 na análise de dados qualitativos", Talarico et al. (2019) apresentam dados

1 Instituição: Universidade Federal de Alagoas, Orcid: https://orcid.org/0000-0003-2900-0322, E-mail: nadson.araujo@gmail.com 2 Instituição: Universidade Federal de Alagoas, Orcid: https://orcid.org/0000-0002-4556-282X, E-mail: adricavalcanty@hotmail.com 3 A resenha foi produzida entre abril e maio de 2020, período em que o Brasil e o mundo enfrentavam uma pandemia causada pelo novo coronavírus (a COVID-19). Uma das principais ações de enfrentamento e contenção da pandemia foi a aplicação de isolamento/distanciamento social. 
de uma pesquisa realizada no ensino superior em uma universidade privada, propondo analisar pressupostos teóricos e práticos a partir da escrita de narrativas de sujeitos professores em processo de formação, uma pesquisa qualitativa que se deu através da utilização do software NVivo 11. Nos resultados da pesquisa, os autores consideram que, incorporar estratégias didáticas no currículo por meio de narrativas digitais, constituiu-se numa contribuição significativa para a formação dos docentes, bem como para fazê-los refletir sobre sua práxis.

Em seguida, no segundo capítulo, intitulado "Inovar na pedagogia universitária para a sociedade do conhecimento", Sales, Sales e Viana (2019) tecem uma discussão no sentido de refletir sobre a práxis do professor do ensino superior, focalizando as possibilidades de redimensionar os processos de ensino em sala de aula, provocando nos docentes a sensibilização em repensar e ou reavaliar seus recursos e métodos de trabalho. Nesse sentido, percebemos a importância de o professor de quaisquer níveis, etapas ou modalidades de ensino, buscar formação e ressignificar suas estratégias de ensino, adaptando-as as realidades locais e as culturas de seus estudantes.

No terceiro capítulo, intitulado "Desafios metodológicos à investigação interdisciplinar", Motta e Viana (2019) abordam questões de interdisciplinaridade, com foco nos desafios metodológicos à investigação interdisciplinar. Segundo a produção, esse processo (de interdisciplinaridade) é determinante na construção de uma educação a luz da sabedoria, da coragem e da humildade (MOTTA; VIANA, 2019). Nesse sentido, os autores apresentam preocupação em pensar uma educação para a formação humana, edificada e com práticas da liberdade.

No quarto capítulo, intitulado "A sala de aula online como espaço de formação continuada de professores da UFAL", Santos e Viana (2019) discorrem sobre a sala de aula online. E, nesse contexto, discorrem sobre esse modelo de sala de aula como espaço de formação continuada de professores em uma universidade pública federal. O capítulo dialoga sobre os usos das tecnologias digitais no trabalho docente, expondo assim, a necessidade de uma incorporação de tais práticas pelos docentes. Ao lermos referido capítulo, percebemos a importância de as instituições de ensino proporem programas de formação continuada para os docentes, sobretudo, a respeito dos usos das tecnologias digitais educacionais para aplicação em aulas.

O quinto capítulo, intitulado "Aprendizagem mediada por tecnologias e mídias digitais: uma linguagem hipertextual", Motta e Viana (2019) apresentam uma discussão sobre a aprendizagem mediada por tecnologias e pelas mídias digitais, com foco na linguagem hipertextual. No texto, os autores ressaltam os desafios impostos pela necessidade de formar professores e de manter programas de formação continuada no sentido de explorar os recursos digitais e as potencialidades deste nas contribuições em atividades de ensino, pesquisa e extensão. Os procedimentos de coleta de dados foram aplicados por meio do ambiente virtual de aprendizagem (AVA). Os autores defendem a necessidade de formação continuada para aquisição dos letramentos digitais, conhecimento indispensável para a interação com as juventudes que interagem com contextos de cultura digital.

No sexto capítulo, intitulado "Ambiente virtual de aprendizagem Moodle" Motta e Viana (2019) discorrem sobre o ambiente virtual de aprendizagem (AVA) Moodle. Nesse sentido, os autores defendem que o ambiente Moodle oportuniza a realização de experimentações diversas: atividades cognitivas, lúdicas, o trabalho com objetos virtuais de aprendizagem (OVA), 
provocações, discussões e atividades que garantem interação entre os sujeitos participantes de tais atividades, os usuários. Concordamos com o entendimento dos autores, advogamos que de fato os ambientes virtuais quando estrategicamente utilizados, podem potencializar os processos de ensino e aprendizagem, contudo, acreditamos que é através de formação continuada e treinamento efetivo dos usuários que se garante êxito quanto a utilização dos ambientes virtuais.

No sétimo capítulo, intitulado "Sala de aula invertida na formação pedagógica de professores universitários: conhecimento, tecnologia e inovação", Viana, Lima e Santos (2019) apontam a sala de aula invertida como estratégia para formação de professores universitários. $\mathrm{Na}$ seção, os pesquisadores defendem que o ensino superior está permeado pelas tecnologias digitais e há a necessidade de práticas docentes inovadoras. Na concepção dos pesquisadores, o grande desafio nesse contexto é ensinar a pensar, provocando a curiosidade e a inteligência do aprendiz, despertando nele, um sujeito com processos de aprendizagem autônoma e reflexiva. Nesse sentido, eles acreditam que a sala de aula invertida pode ser uma excelente estratégia para alcançar esse objetivo.

No oitavo capítulo, intitulado "O discurso da qualidade na educação: a voz de professores", Silva, Silva e Gomes (2019) discorrem sobre a concepção que têm os professores a respeito da qualidade da educação. A pesquisa foi realizada por meio de um questionário aplicado com quatro professores que atuavam na educação básica em uma escola pública localizada no interior do Estado de Alagoas. Na seção, os autores ressaltam a importância de observar a qualidade da educação como garantia da formação humana. Os professores entrevistados reconhecem o papel e a responsabilidade do Estado na garantia de uma educação de qualidade para todos.

No último capítulo da coletânea, o nono, intitulado "O uso do DSCSoft na análise de dados qualitativos: sobre as sessões de relatos de experiências no V Web currículo", Viana e Iwata Neto (2019) abordam o uso do DSCSoft para a análise de dados qualitativos. A pesquisa foi realizada numa universidade paulista e tinha por objetivo reconstruir os discursos individuais e coletivos dos participantes em dados coletados, previamente, por meio de aplicação de questionário. Nessa direção, os pesquisadores perceberam que a utilização do software possibilitou que eles - os pesquisadores - chegassem aos produtos registrados enquanto discurso coletivos, socialmente compartilhados e presentes nos registros individuais coletados. Como categorias de análise foram destacadas: os recursos utilizados, a formação dos professores, a prática pedagógica, compartilhamento de experiências e conhecimentos de novas possibilidades.

Como anunciamos no início desta resenha, estamos vivenciando tempos de enfrentamento a pandemia da COVID-19, e, como nunca antes o fizemos, iniciamos um processo de reflexão sobre nossas práticas docentes e suas influências na formação humana, no sentido de preparar e formar os sujeitos para as interações socias estabelecidas por meio da conectividade e interatividade, inerentes a contextos de uma sociedade permeada por tecnologias digitais.

A obra resenhada apresenta-nos uma diversidade de recursos digitais e estratégias didáticas que podemos utilizar em práxis e em contextos de educação híbrida, online ou remota. Recomendamos a obra para os que queiram se aprofundar nos estudos sobre metodologias ativas para e educação. Por se tratar de um livro inédito, sua leitura se torna essencial para 
aqueles que buscam aprimoramento de sua prática docente, sobretudo, para o ensino superior e na formação continuada de professores.

\section{REFERÊNCIAS}

MOTTA, Allana Roberta V; VIANA, Maria Aparecida Pereira. Desafios metodológicos à investigação interdisciplinar. In: VIANA, Maria Aparecida Viana; SILVA, Givanildo da. Tempos de cibercultura, narrativas e currículo: potencialidades educativas (Orgs). Maceió: Edufal, 2019.

PIMENTEL, Fernando Silvio Cavalcante; COSTA, Cleide Jane de Sá Araújo. A cultura digital no cotidiano das crianças: apropriação, reflexos e descompassos na educação formal. In: COSTA, Cleide Jane de Sá Araújo; PINTO, Anamelia de Campos (Orgs.). Tecnologias digitais da informação e comunicação na educação. Maceió: Edufal, 2017.

SANTOS, Adriana Cavalcanti dos; SANTOS, Wilton Petrus dos; SANTOS, Nádson Araújo dos. A produção textual em contextos do letramento e significação social. Horizontes, [S.1.], v. 38, n. 1, p. e020006, fev. 2020. ISSN 2317-109X. Disponível em: <https://revistahorizontes.usf.edu.br/ horizontes/article/view/846>. Acesso em: 20 maio 2020. doi:https://doi.org/10.24933/horizontes. v38i1.846.

SANTOS, Nádson Araújo dos; CAVALCANTE, Maria Auxiliadora da Silva. Gêneros textuais e tecnologias digitais na escola: diálogos possíveis. In: SANTOS; Adriana Cavalcanti dos; SANTOS, Nádson Araújo dos (org). Educação e linguagem: interfaces de investigação em rede. Maceió: Edufal, 2019. 